\title{
Morphometric Study of Spleen in Iranian Cadavers from Razavi-Khorasan Province
}

\author{
Mohammadi $\mathrm{S}^{1}$, Hedjazi A ${ }^{2}$, Sajjadian $\mathrm{M}^{2}$, Kebriaei $\mathrm{SMM}^{2}$, Naser Ghrobi ${ }^{2}$, Yaghmaei $\mathrm{A}^{2}$ \\ Moghadam $\mathrm{MD}^{3}$, Mohammadi $\mathrm{M}^{4}$ \\ ${ }^{1}$ Department of Anatomy and Cell Biology, School of Medicine, Mashhad University of Medical Sciences, \\ Mashhad, Iran \\ ${ }^{2}$ Mashhad Legal Medicine Research Center, Legal Medicine Organization, Mashhad, Iran \\ ${ }^{3}$ Department of Community Medicine, School of Medicine, Mashhad University of Medical Sciences, \\ Mashhad, Iran \\ ${ }^{4}$ Department of Public Health, School of Health, Shahid Beheshti University of Medical Sciences, Tehran, \\ Iran \\ e-mail:mohammadish@mums.ac.ir
}

\begin{abstract}
Anthropologic parameters of the spleen are important because many diseases present with reduction or enlargement of the spleen. No data exists about the standard dimensions of the normal spleen in Iranian population. Therefore, the objective of the study was to investigate anthropologic parameters of the spleen in Iranian cadavers. In 2014-2015, this cross sectional study was undertaken from the Razavi Khorasan Province of Iran. Iranian cadavers ( $n=693$, 152 female/541 male) with no history of poisoning, drug or alcohol addiction, no gross abnormality and injury of the spleen were included in the study. The length, width and thickness of spleen were measured using a Vernier caliper. The mean values of the demographic data were age $=40.28 \pm 20.97$ years; weight $=63.68 \pm 17.40 \mathrm{~kg}$; height $=160.03 \pm 28.45 \mathrm{~cm}$ and BMI $=25.03 \pm 20.46 \mathrm{~kg} / \mathrm{m}^{2}$. The mean values of the spleen length, width, thickness, notch, weight and index in the cadavers were $11.32 \pm 3.10 \mathrm{~cm}, 8.05 \pm 2.35 \mathrm{~cm}, 20.12 \pm 9.21 \mathrm{~mm}, 0.84$ $\pm 1.35,123.87 \pm 82.46 \mathrm{~g}$, and $2.01 \pm 1.40$, respectively. Accessory spleen was found in five cadavers. The anthropologic parameters of the spleen showed significant difference between males and females except for index of the spleen. Having standard data on the spleen is useful for radiologists, surgeons, anatomists and anthropologists. The results of the study may provide valuable data in the standardization of the anthropologic parameters of the spleen in the Iranian population.
\end{abstract}

Key words: Spleen; Cadaver; Anatomic variation.

\section{Introduction}

The spleen consists of a large lymph node and is located in the left hypochondriac region of the abdomen, anterior to the left kidney and posterior to the stomach. ${ }^{1}$ The spleen has two surfaces; diaphragmatic and visceral; it has two margins, superior and inferior. ${ }^{1}$ The diaphragmatic surface separates the spleen from the ninth, tenth, and eleventh left ribs. The visceral surface is divided by a low ridge into two regions: gastric and renal regions. ${ }^{2}$ The splenic hilum corresponds to the long axis of the tenth left rib. ${ }^{2}$ Besides, the spleen plays important roles such as destruction of red cells, formation of activated lymphocytes, defense against microorganism and blood storage. ${ }^{3}$

In the text book of Moore's Anatomy has been mentioned that the values of the spleen length, breath and thickness are $12 \mathrm{~cm}, 6 \mathrm{~cm}$ and $2 \mathrm{~cm}$, respectively. ${ }^{8}$ The range of the spleen in Asia is reported to range between 5 and $20 \mathrm{~cm}$, while the width is reported to range between 0.5 and 10.5 $\mathrm{cm} .{ }^{9-12}$ The thickness of the spleen ranges from 2 to $9.5 \mathrm{~cm}$, while the range of the spleen weight was $48-720$ grams. ${ }^{9-13}$ The incidence of the 
splenic notches was $50-98.33 \%$ in Asian population . $^{11,14-17}$

Spleen bud appears as a mesodermal proliferation in the dorsal mesogastrium in the fifth week of gestation. ${ }^{4}$ Lienorenal ligament forms by extension of dorsal mesogastrium between the spleen and the left kidney, while gastro splenic ligament develops by extension of dorsal mesogastrium between the spleen and the stomach. ${ }^{4}$ During the fetal period, lymphocytes migrate to the spleen bud. In early stage of development, the spleen is lobulated but the lobules fuse with each other before birth. ${ }^{5}$ The notches on the spleen border are considered as remnants of the sulcus that separated the spleen lobules in the fetal life. Palpation of the splenic notches is an important clinical sign that can indicate the enlarged spleen in cases of splenomegaly. ${ }^{6}$

Anthropologic variables of the spleen are critical due to many diseases present with reduction or enlargement of the spleen. ${ }^{7}$ No data exists about the standard dimensions of the normal spleen in Iranian population. Hence, the present study was conducted to determine anthropologic values of the spleen in Iranian cadavers.

\section{Materials and Methods}

A cross sectional study was carried out in the dissection hall of the Forensic Medicine Organization, Razavi Khorasan province, from June 2014 to July 2015. The protocol of the research was approved by the Ethics Research Committee of Mashhad Legal Medicine Organization.

Six hundred and ninety-three spleens (541 males, 152 females) were excised from cadavers in the dissection hall of Mashhad Forensic Medicine Organization cadavers. They were divided into 10 different age groups: Group I (0- 9 years), Group II (10- 19 years), Group III (20- 29 years), Group IV (30- 39 years), Group V (40- 49 years), Group VI (50- 59 years), Group VII (60- 69 years),
Group VIII (70- 79 years), Group IX (80- 89 years) and Group X (90- 99 years).

Iranian cadavers with no history of poisoning, alcohol or drug abuse, no sign of decomposition and no evidence of trauma or abnormality of spleen were included in the study. Exclusion criteria were as follows: Non-Iranian cadavers and cadavers with any pathologic abnormality were excluded. Demographic data including age, gender, body weight and height were collected from each cadaver. The index was also calculated as spleen weight/body weight. Besides, Body Mass Index (BMI) was calculated as weight (kg/height $\mathrm{m}^{2}$ ).

The abdomen was opened by a single incision from mental to pubic symphysis. After reflecting the peritoneum, spleens were washed with tap water. The length of the spleen was measured from the superior pole to the inferior pole using a Vernier caliper (figure 1).

Figure 1. (A-F) are images of the spleens in different cadavers that were measured using a Vernier caliper.
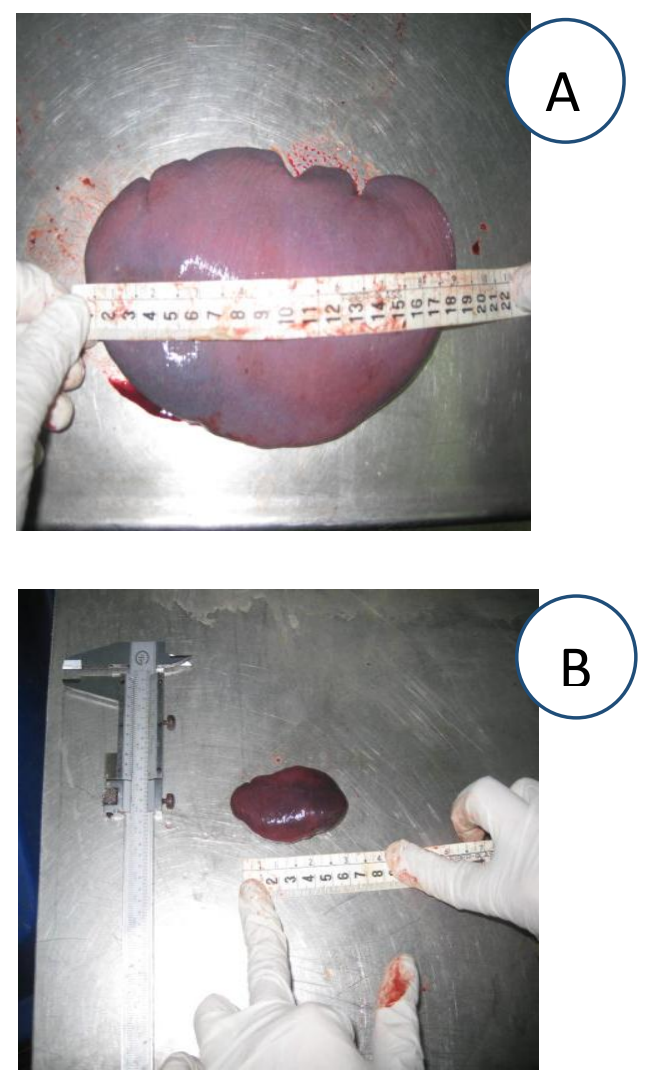

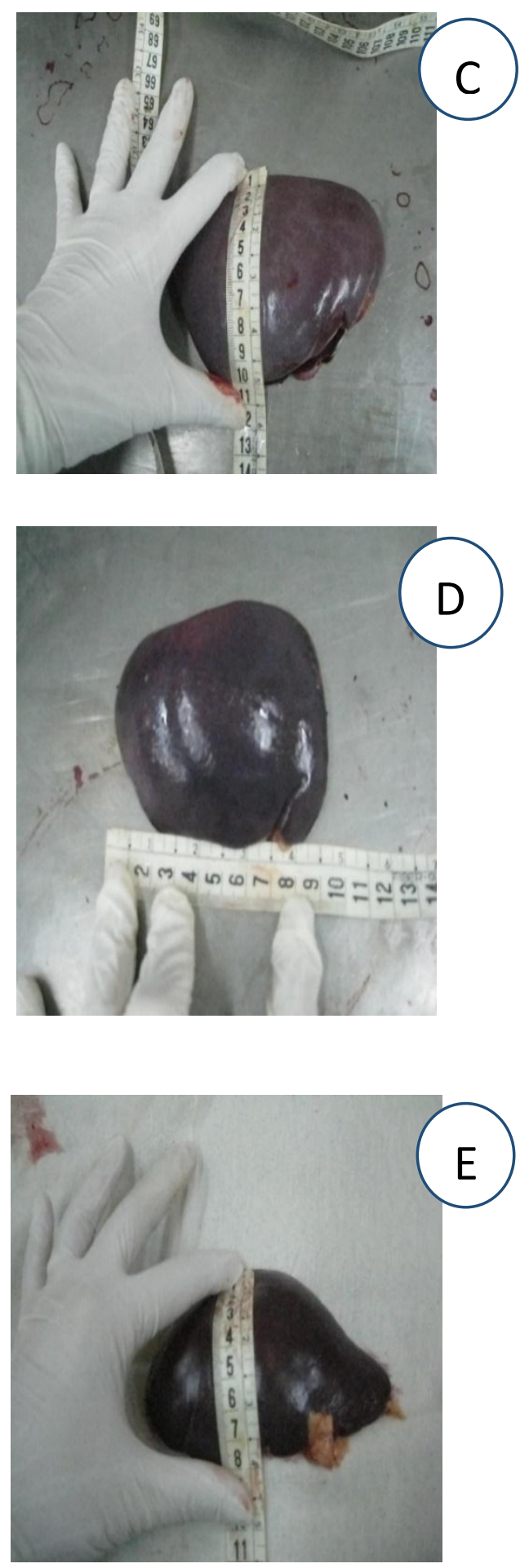

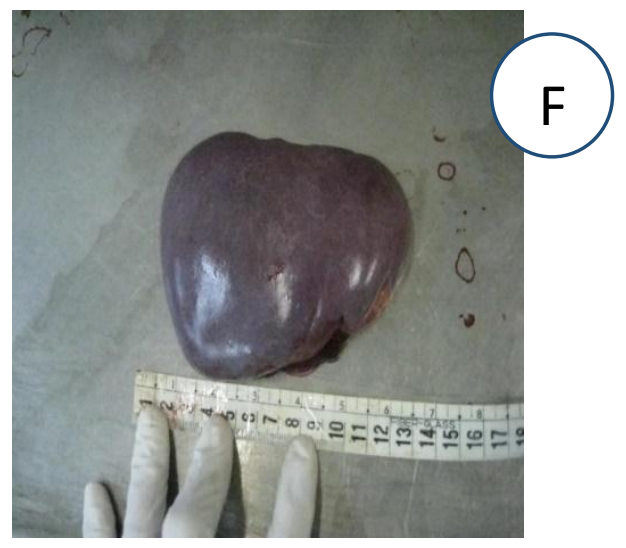

Caliper calibration performed previously based on ISO guidelines. The width of the spleen was considered between the superior and inferior pole of the spleen at the plane perpendicular to the length. The greatest distance between the anterior and posterior surface of the spleen at the hilum level was considered to be its thickness. Besides, the spleen weight was measured with the help of an electronic weighing machine (Pand Azma 3100, Iran). The notches and accessory spleens, if they were present, were observed meticulously. Measurement for all cadavers were performed by a single anatomist. Photographs were taken using a Canon digital camera.

Statistical analysis: Values were presented as mean \pm SD. All data were analyzed using SPSS 20.0 for windows. A $p<0.05$ was considered significant. The normality of data was assessed using the Kolmogorov-Smirnov test. The correlation between anthropometric parameters and variances such as spleen length was evaluated using the Spearman correlation. Normally distributed data were analyzed using independent sample t-tests (for two groups) or one-way analysis of variance (for more than two groups).

\section{Results}

Demographic data for the cadavers including age, gender, weight and height are summarized in table I. 
Table I. Demographic characteristics of Iranian cadavers $(\mathrm{N}=693)$ in Razavi Khorasan province, Iran

\begin{tabular}{ccccc}
\hline $\begin{array}{c}\text { Age } \\
\text { groups }\end{array}$ & Age (years) & $\begin{array}{c}\text { Gender } \\
(\mathrm{F} / \mathrm{M})\end{array}$ & Height $(\mathrm{m})$ & Weight $(\mathrm{kg})$ \\
\hline$<10$ & $1.98 \pm 2.77$ & $21 / 26$ & $72.59 \pm 36.98$ & $12.68 \pm 19.85$ \\
$10-19$ & $15.86 \pm 2.63$ & $11 / 47$ & $161 \pm 16.31$ & $60.65 \pm 16.35$ \\
$20-29$ & $24.61 \pm 2.70$ & $31 / 93$ & $167.95 \pm 7.63$ & $67.70 \pm 8.17$ \\
$30-39$ & $34.33 \pm 2.67$ & $23 / 95$ & $166.61 \pm 16.85$ & $69.12 \pm 9.27$ \\
$40-49$ & $44.51 \pm 2.56$ & $20 / 113$ & $166.63 \pm 11.40$ & $68.21 \pm 9.76$ \\
$50-59$ & $53.78 \pm 2.87$ & $14 / 65$ & $168.32 \pm 6.99$ & $68.97 \pm 6.98$ \\
$60-69$ & $63.44 \pm 2.66$ & $12 / 49$ & $164.39 \pm 22.12$ & $68.09 \pm 5.83$ \\
$70-79$ & $74.07 \pm 2.56$ & $11 / 31$ & $167.35 \pm 7.64$ & $67 \pm 7.30$ \\
$80-89$ & $83.52 \pm 3.23$ & $8 / 15$ & $165.91 \pm 5.27$ & $64.34 \pm 6.75$ \\
$90-99$ & $91.25 \pm 2.18$ & $1 / 7$ & $166.75 \pm 6.73$ & $61.87 \pm 14.28$ \\
\hline
\end{tabular}

Table II. Length, width, thickness, notch, weight and index of the spleen in Iranian cadave

\begin{tabular}{ccccccc}
\hline $\begin{array}{c}\text { Age } \\
\text { groups }\end{array}$ & $\begin{array}{c}\text { Length } \\
(\mathrm{cm})\end{array}$ & $\begin{array}{c}\text { Width } \\
(\mathrm{cm})\end{array}$ & $\begin{array}{c}\text { Thickne } \\
\text { ss }(\mathrm{mm})\end{array}$ & Notches & $\begin{array}{c}\text { Weight } \\
(\mathrm{g})\end{array}$ & Index \\
\hline$<10$ & $4.15 \pm 3$. & $2.75 \pm 2.48$ & $7.06 \pm 7.6$ & $1.46 \pm 1.6$ & $20.89 \pm 2$ & $2.72 \pm 2.8$ \\
& 15 & & 1 & 2 & 5.6 & \\
$10-19$ & $11.15 \pm$ & $8.3 \pm 1.54^{*}$ & $18.98 \pm 6$. & $1.20 \pm 1.4$ & $113.32 \pm$ & $1.93 \pm 0.91$ \\
& $2.29 *$ & 5 & $84^{*}$ & 1 & $54.46^{*} \#$ & \\
$20-29$ & $12.21 \pm$ & $8.65 \pm 1.86$ & $20.04 \pm 6$. & $0.94 \pm 1.2$ & $132.15 \pm$ & $1.94 \pm 0.99$ \\
& $2.51^{*}$ & $*$ & $348^{*}$ & 9 & $71.17 *$ & $*$ \\
$30-39$ & $11.57 \pm$ & $8.36 \pm 1.96$ & $19.57 \pm 6$. & $0.88 \pm 1.3$ & $126.85 \pm$ & $1.84 \pm 0.91$ \\
& $2.46^{*}$ & $*$ & $86^{* \# \#}$ & 1 & $63.66^{*}$ & $*$ \\
$40-49$ & $12.32 \pm$ & $8.67 \pm 1.83$ & $21.93 \pm 7$. & $0.91 \pm 1.4$ & $153.35 \pm$ & $2.26 \pm 1.48$ \\
& $2.65^{*}$ & $*$ & $59^{*}$ & 8 & $101.92^{*}$ & \\
$50-59$ & $11.68 \pm$ & $8.24 \pm 1.81$ & $23.50 \pm 1$ & $0.34 \pm 0.8$ & $114.09 \pm$ & $1.67 \pm 0.66$ \\
& $2.01^{*}$ & $*$ & $0.70^{*}$ & 6 & $46.64^{*}$ & $*$ \\
$60-69$ & $11.63 \pm$ & $8.39 \pm 1.48$ & $22.91 \pm 1$ & $0.39 \pm 0.9$ & $114.09 \pm$ & $1.67 \pm 0.66$ \\
& $1.62^{*}$ & $*$ & $1.53^{*}$ & 7 & $46.64 * \#$ & $*$ \\
$70-79$ & $11.45 \pm$ & $7.98 \pm 1.88$ & $21.01 \pm 7$. & $0.95 \pm 1.6$ & $121.38 \pm$ & $1.81 \pm 1.03$ \\
& $2.01^{*}$ & $*$ & $26^{*}$ & 6 & $70.01 *$ & \\
$80-89$ & $12.22 \pm$ & $8.40 \pm 1.88$ & $21.63 \pm 1$ & $0.47 \pm 0.9$ & $149.09 \pm$ & $2.44 \pm 3.32$ \\
& $2.69 *$ & $*$ & $6.54^{*}$ & 9 & $186.81^{*}$ & \\
$90-99$ & $11.65 \pm$ & $7.93 \pm 1.98$ & $20.87 \pm 5$. & $0.62 \pm 1.7$ & $110.62 \pm$ & $1.80 \pm 0.97$ \\
& $1.40^{*}$ & $*$ & $61^{*}$ & 6 & 59.91 & \\
\hline
\end{tabular}

Values are expressed as mean \pm SD. Comparison between groups was made using ANOVA and Tukey test.

$* p<0.05$ compared to Group I within column. \# $p<0.05$

compared to group $\mathrm{V}$ within column. \# \# $p<0.05$ compared to Group VI within column.

different gender and age groups are shown in table II and III. The mean length of the spleen was 11.32 $\mathrm{cm}$ (range, 0.5 to $22 \mathrm{~cm}$ ). The average width and thickness of the spleen was measured $8.05 \mathrm{~cm}$ (range, 0.5 to $15 \mathrm{~cm}$ ) and $2.01 \mathrm{~cm}$ (range, 0.05 to $9.5 \mathrm{~cm}$ ). Minimum index of the spleen was 0.04 and the maximum weight of the spleen was 14.29. The weight of the spleen varied from 1 to 720 with a mean value of 123.87 .

Table III. Length, width, thickness, notch, weight and index of the spleen of Iranian cadavers of different genders

\begin{tabular}{lccccll}
\hline Gender & $\begin{array}{c}\text { Length } \\
(\mathbf{c m})\end{array}$ & $\begin{array}{c}\text { Width } \\
(\mathbf{c m})\end{array}$ & $\begin{array}{c}\text { Thickness } \\
(\mathbf{m m})\end{array}$ & Notches & Weight $(\mathbf{g})$ & Index \\
\hline \multirow{2}{*}{ Female } & $10.67 \pm 3$. & $7.51 \pm 2.7$ & $18.61 \pm 8.30^{*} 0.80 \pm 1.28$ & $107.23 \pm 65.2 .12 \pm 1.74$ \\
& $46 \#$ & $8^{* *}$ & & & $45^{* *}$ \\
Male & $11.50 \pm$ & $8.20 \pm 2.1$ & $20.55 \pm 9.41$ & $0.86 \pm 1.37$ & $128.51 \pm 8$ & $1.98 \pm 1.29$ \\
& 2.97 & 9 & & 6.09 & \\
\hline Values are presented as mean \pm SD. Independent samples t-test was used to
\end{tabular}

Values are presented as mean \pm SD. Independent samples t-test was used

compare, $* p=0.02, \quad p=0.005, p=0.004$, between gender in cadavers**

The mean age of cadavers was $40.46 \pm 20.99$ $($ Mean \pm SD) years. Of the cadavers $152(21.9 \%)$ were females and $541(78.1 \%)$ were males. The values obtained for height ranges from 1 to 190 , with an average of $160.03 \mathrm{~cm}$. The weight of cadavers ranges between 1 and 120, with an average of $63.68 \mathrm{~g}$. The mean value of body mass index was $25.20 \pm 26.41 \mathrm{~kg} / \mathrm{m}^{2}$.

The splenic notches were found in 435 cadavers (37.22\%). The splenic notches on the superior border of the spleen ranges between zero and six, with an average of $0.62 \pm 1.03$. The notches on the inferior border of the spleen ranges from zero to five, with an average of $0.23 \pm 0.65$. The highest value of spleen notch was observed in Group I, and the lowest value of spleen notch was found in Group IX. Accessory spleen was present in five cadavers $(0.7 \%)$.

Table IV. Correlation (r) between demographic data and anthropometric parameters of spleen.

\begin{tabular}{ccccccc}
\hline & $\begin{array}{c}\text { Length } \\
(\mathrm{cm})\end{array}$ & $\begin{array}{c}\text { Width } \\
(\mathrm{cm})\end{array}$ & $\begin{array}{c}\text { Thickness } \\
(\mathrm{mm})\end{array}$ & Notches & $\begin{array}{c}\text { Weight } \\
(\mathrm{g})\end{array}$ & Index \\
\hline Age & $0.172^{*}$ & $0.130 \#$ & $0.227^{*}$ & -0.030 & $0.118^{* *}$ & -0.035 \\
Height & $0.266^{*}$ & $0.135^{*}$ & $0.225^{*}$ & 0.066 & $0.325^{*}$ & $0.096 \# \#$ \\
Body & $0.212^{*}$ & $0.139^{*}$ & $0.230^{*}$ & $0.119^{* *}$ & $0.288^{*}$ & -0.054 \\
$\begin{array}{c}\text { weight } \\
\text { BMI }\end{array}$ & $0.120^{* * *}$ & $0.158^{*}$ & $0.161^{*}$ & 0.071 & $0.150^{*}$ & $-0.115^{* * *}$ \\
\hline
\end{tabular}

Correlations were assessed using Spearman correlation coefficients. $* p=0.000, * * p=0.006$, *** $p=0.002$, *** $p=0.008$, $p=0.001, p=0.02$

The spleen length was the greatest in Group IV, while the shortest length was observed in Group I. The highest width of spleen was seen in cadavers 40-49 years old, while the lowest width of spleen was observed in cadavers $0-9$ years old. The spleen thickness was the greatest in Group V, while the shortest thickness was observed in Group I. The maximum weight of spleen was in fourth decade of life, while the minimum weight of spleen was observed in $1^{\text {th }}$ decade of life. The highest value of spleen index was found in Group I, while the lowest value of spleen index was observed in Group V and VI.

As shown in Table III, the anthropologic parameters of spleen except spleen index were significantly higher in males than females ( $p$ $<0.05$ ). Spearman's correlation showed a strong correlation between anthropologic parameters of the spleen and demographic values of cadavers.

\section{Discussion}

The results of this study showed that the spleen length, width and thickness were $11.32 \mathrm{~cm}, 8.05$ 
and $2.01 \mathrm{~cm}$, respectively. In addition, the average of spleen weight was $123.87 \mathrm{~g}$. The spleen sizes were significantly higher in males than females.

In the text book of Gray's Anatomy has been described that the spleen is usually $12 \mathrm{~cm}$ length, $7 \mathrm{~cm}$ width and 3 to $4 \mathrm{~cm}$ thickness, respectively. ${ }^{2}$ In the present study, the mean values of the spleen length, breath and thickness in the cadavers were $11.32 \mathrm{~cm}, 8.05 \mathrm{~cm}$ and $2.12 \mathrm{~cm}$, respectively.

The mean length of the spleen was $9.66 \mathrm{~cm}$ (range, 5 to $13 \mathrm{~cm}$ ) in India. ${ }^{9}$ The average width and thickness of the spleen were $3.06 \mathrm{~cm}$ (range, 1.5 to $5.5 \mathrm{~cm}$ ) and $6.22 \mathrm{~cm}$ (range, 3.5 to $9.5 \mathrm{~cm}$ ), respectively. The spleen sizes were more in our population than that seen in this study except for the spleen thickness. Similarly, there was a significant association between the spleen length with age, gender and height. The spleen length was the shortest in cadavers $0-15$ years old that was nearly the same with that of the current study results. ${ }^{10}$

In another report, Rayhan and colleagues observed the greatest length and width of spleen in cadavers 40-49 years old and the greatest thickness of the spleen in cases 50-59 years old, which was consistent with this findings. ${ }^{11}$

In another Turkish study, the spleen length was $12.8 \mathrm{~cm}$ (range, 8.5 to $20 \mathrm{~cm}$ ). The mean width of the spleen ranges between 5 and 10.5, with an average $8.2 \mathrm{~cm}$. The diameter of spleen varied from two to six with a mean value of $3.7 \mathrm{~cm}$. There was a statistically significant correlation between the spleen size and demographic values. 12 The spleen size was less in our population than that seen in this study except for the spleen thickness. These differences might be due to the race or genetic factors of specimens.

According to Gray's Anatomy, the range of the spleen weight is $80-300$ grams, with an average of 150 grams. $^{2}$ The weight of the spleen varied from 1 to 720 with mean value of 123.87 grams in the present study. In a study in Kumaon Region of India, ${ }^{20}$ the spleen weight in females was more than males (153.9 g vs. $149.17 \mathrm{~g}$, respectively), which was inconsistent with our findings. In a Turkish study by Caglar and colleagues, the range of the spleen weight was 48-720 grams, with an average 209 grams. In that study, the spleen weight was significantly correlates with height. ${ }^{12}$ Similarly, the maximum weight of the spleen was found 720 grams. In addition, a significant correlation exists between height and the spleen weight.

In Korean population, the mean weight of the spleen was 99.51 grams in female and 115.29 grams in male. ${ }^{21}$ In another study in Thailand, the mean weight of the spleen was 104 grams in male and 77 grams in female. ${ }^{22}$ Besides, the spleen weight was strongly correlates with age, body weight and height in males, but not in females. That spleen of males was heavier than females. However, the spleen weight was significantly correlates with age, weight and height for both genders. In the text book it is noted that near the superior margin of the spleen there may be one or two notches. ${ }^{2}$ Nayak and colleagues reported the incidence of the splenic notches in 50\% of Indian population. ${ }^{14}$ In other studies in India, splenic notches were observed in $98 \%$ (Das et al., 2008), $98.33 \%,{ }^{16} 88.57 \%{ }^{11}$ and $84 \%{ }^{17}$ of cases, respectively. The splenic notches reported in $98 \%$ of the normal population in Malaysia. ${ }^{15}$ The splenic notches were found in $37.22 \%$ of cadavers in the present study. Findings of the study showed that the incidence of splenic notches was less than that in Asian population. This may mean that there was an excellent fusion of all the splenic masses during fetal life.

Results of the current study should be interpreted in light of its limitations. The limitation of this study was that most of our sample was males, which may result in some bias. In the present study, the volume and vessels of spleen did not examine. Hence, recommend that future researches focus on it. This study is the first to investigate standard anthropologic values of the spleen in Iranian population.

\section{Conclusion}

Having standard data on the spleen is useful for radiologists, surgeons, anatomists and anthropologists. The results of the present study will provide valuable data in the standardization of the anthropologic parameters of the spleen in the Iranian population. However, further studies with a larger population are required to complete 
anthropologic information of the spleen in Iranian citizens.

Acknowledgment: The authors would like to thank the Mashhad Legal Medicine Organization for their financial support to conduct this study.

\section{References}

1. Snell R. Clinical Anatomy by Regions. 9th ed. Philadelphia: Lippincott Williams \& Wilkins; 2012.

2. Borley N. Spleen in Standring S Gray's Anatomy. $40^{\text {th }}$ ed. London: Churchill Livingstone: Elsevier; 2008.

3. Junqueira LC, Carneiro J, Long JA. Junqueira's Basic Histology. $5^{\text {th }}$ ed. Brazil: Lange Medical Publication, California; 2010.

4. Sadler, T W. Langman, Jan. Medical Embryology. $10^{\text {th }}$ ed. Philadelphia: Lippincott Williams \& Wilkins; 2006.

5. Sant S. Embryology for Medical Students. New Delhi: Jaypee Brother's Medical Publishers (p) Ltd.; 2002.

6. Camitta BM. Nelson Textbook of Pediatrics. In: Kliegman RM, Behrman RE, Jenson HB, Staton BF. Editors. Splenomegaly. Philadelphia: $18^{\text {th }}$ ed. Pa: Saunders; 2007. p. 2091

7. Lamb PM, Lund A, Kanagasabay RR, Martin A, Webb JAW, Reznek RH. Spleen size: how well do linear ultrasound measurements correlate with threedimensional CT volume assessments? $\mathrm{Br} \mathrm{J}$ Radiol 2002; 75(895): 573-77.

8. Moore KL, Dally AF. Clinically oriented anatomy. $7^{\text {th }}$ ed. Philadelphia: Lippincott Williams \& Wilkins; 2011.

9. Chowdhury AI, Sultana SZ, Mannan S. Morphometric study of splenic volume in Bangladeshi cadaver. Mymensingh Med Journal. 2012; 21(3):445-49.

10. Chowdhury AI, Khalil M, Begum JA, Rahman MH, Mannan S, Sultana SZ et al. Gross anatomical study of splenic length. Mymensingh Medical Journal. MMJ 2009; 18(1 Suppl): S34-39.

11. Rahyan KA, Nurunnabi ASM, Kishwara S, Noor M. Morphometric study of the postmortem human spleen. J Dhaka Med Coll. 2011; 20(1): 32-36.
12. Caglar V, Kumral B, Uygur R, Alkoc OA, Ozen OA, Demirel H. Study of Volume, Weight and Size of Normal Pancreas, Spleen and Kidney in Adults Autopsies. Forensic Medicine and Anatomy Research. 2014; 2: 63-69.

13. Tanna JA, Patel PN, Kalele SD. Relation between Organ Weights and Body Weight in Adult Population of Bhavnagar Region- A Post-Mortem Study. J Indian Acad Forensic Med. 2011, 33(1): 57-59.

14. Nayak BS, Somayajiand SN, Soumya KV. A Study on the Variations of Size, Shape and External Features of the Spleen in South Indian Population. Int J Morphol. 2011; 29:675-77.

15. Das S, Abd Latiff A, Suhaimi FH, Ghazalli H, Othman F. Anomalous splenic notches: a cadaveric study with clinical importance. Bratisl Lek Listy. 2008; 109 (11):513-16.

16. Patil GV, Shishirkumar, Apoorva D, Thejeswari, Sharif J, C Sheshgiri et al. Study of Splenic notches in a human cadaver. International Journal of Recent Advances in Multidisciplinary Research. 2014; 1(2): 1-3.

17 Setty S, Katikiredd RS. A Cadaveric Study of Human Splenic Notches and Fissures .International Journal of Health Sciences \& Research September 2013; 40(3): 40-44.

18. Das S, Abd Latiff A, Suhaimi FH, Ghazalli H, Othman F. Anomalous splenic notches: a cadaveric study with clinical importance. Bratisl Lek Listy. 2008; 109: 513-16.

19. Borley N. Spleen in Standring S Gray's Anatomy. $40^{\text {th }}$ ed. London: Churchill Livingstone Elsevier; 2008.

20. Chandra Prakash, D. Deopa, Thakkar HK. Study of Internal Organ Weight and Its Correlation to Body Weight in Kumaon Region of Uttarakhand .J Indian Acad Forensic Med. 2013; 35(1): 29-32.

21. Sheldon WH, Stevens SS, Tucker WB. The Varieties of Human Physique. New York : Herper \& Brothers; 1994

22. Narongchai P, Narongchai S. Study of the normal internal organ weights in Thai population. J Med Assoc Thai. 2008; 91(5):747-53.

23. Chirachariyavej T, Ouyswat K, Sanggarnjanavanich S. Tiensuwan M, Peonim V, Sirikulchayanonta V. Normal Internal Organ Weight of Thai Adults Correlated to Body Length and Body Weight. J Med Assoc Thai. 2006; 89 (10): 1702-12. 